Bartın Üniversitesi

Eğitim Fakültesi Dergisi

Cilt 6, Sayı 1, s. 159-176, Subat 2017

BARTIN - TÜRKIYE

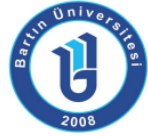

ISSN: 1308-7177
Bartin University

Journal of Faculty of Education

Volume 6, Issue 1, p. 159-176, February 2017

BARTIN - TURKEY

Doi: $10.14686 /$ buefad. 285744

\title{
Ortaokullarda Bilişim Teknolojileri ve Yazılım Dersinin İşlenişi, Yaşanan Problemler ve Çözüm Önerileri: Öğretmen Görüşleri
}

Şefika Şule ERÇETIN, Prof. Dr., Hacettepe Üniversitesi Eğitim Fakültesi, sefikasule@gmail.com

Aykut DURAK, Öğretmen, Milli Eğitim Bakanlığı, aykdur78@gmail.com

Öz: Bu çalışmanın amacı ortaokullarda Bilişim Teknolojileri ve Yazılım dersinin nasıl işlendiğini irdelemek ve bu derste yaşanan problemleri belirlemek olarak belirlenmiştir. Bu amaç doğrultusunda Türkiye'nin 31 farklı ilinde ortaokullarda görev yapan 50 bilişim teknolojileri öğretmeninden 2015-2016 yılının güz döneminde veri toplanmıştır. Karma araştırma yöntemi ile desenlenen bu araştırmada veri toplama aracı olarak araştırmacılar tarafından geliştirilen "demografik bilgi anketi" ve "bilişim teknolojileri dersi işlenişi anketi" ve "bilişim teknolojileri dersinin işleyişinde karşılaşılan engeller ve öneriler" adlı yarı yapılandırılmış görüşme formu kullanılmıştır. Araştırma sonuçlarına göre öğretmenlerin en çok anlatma ile gösterip yaptırma yöntemlerini kullandığı anlaşılmaktadır. Bununla birlikte dersin işlenmesinde birçok bileşenin yoksunluğunun yaşanması nedeniyle çeşitli engellerle karşılaşıldığı sonucuna ulaşılmıştır.

Anahtar Kelimeler: bilişim teknolojileri dersi, bilişim teknolojileri sınıfı, bilişim teknolojileri dersi işlenişi, K-12, öğretmenler.

\section{Processing, Problems and Solution Suggestions of Information Technologies and Software Course in Middle Schools: Teacher Opinions}

\begin{abstract}
It was determined that the purpose of this study was to examine how the Computing Technologies and Software course was taught in middle schools, and to identify the problems that existed in this course. For this purpose, the data was collected from 50 information technology teachers in secondary schools in 31 different provinces of Turkey during the fall semester of 2015-2016. The study was organized with mixed research method developed by the researchers to collect data "demographic questionnaire", "processing of information technologies in the course of the survey" and "semi-structured form of the obstacles and suggestions in the handling of the information technology course" were used. According to the results of the research, it is understood that teachers mostly use metdod of explaining and demonstration method. However, in the processing of the course, many obstacles have been encountered because of the lack of many components.
\end{abstract}

Key Words: Information technology course, information technology class, the processing of the information technology course, K-12, teachers. 


\section{GíRiş}

Günümüzde teknoloji ve teknolojik araç-gereçler günlük hayatın ayrılmaz bir parçası haline gelmiştir. Bu dönüşümle birlikte bilgi toplumu olarak ifade edilen (Erdoğan vd., 2010) günümüzde öğrenenlerden beklentilerde de değişim ve dönüşümler yaşanmaktadır. Bu durumla ilgili olarak literatürde bilgi çağında yoğun emek gerektiren işlerden ziyade bireylerin üst düzey düşünme becerilerini kullanarak bilgi üretmesini gerektirecek işlerin ön plana çıkacağı belirtilmiştir (Bernstein, 1995; Crow, 2006; Morrison, 2012). Bunu sağlamak içinde eğitimde köklü değişiklikler yapılması gerektiğini ifade edilebilir (Bernstein, 1995; Nam, \& Smith-Jackson, 2007). Bunun en önemli nedenlerinden biri de üretilen bilgi miktarının çok kısa sürede birkaç kat artması ve bilginin hızlı bir değişim-dönüşüm geçirmesi olarak gösterilebilir (Crow, 2006; Seferoğlu, 2007). Böyle bir dönemde bireyin her şeyle ilgili bilgi sahibi olması yerine öğrenmeye açık olması (Durdukoca, \& Arıbaş, 2011) ve bunu etkin bir biçimde kullanabilesi (Akkoyunlu, \& Kurbanoğlu, 2003; Akbıyık, \& Seferoğlu, 2012) ön plana çıkmaktadır.

Bu dönemde bireylerden karşılaştığı problem durumlarına çözümler üretme sürecinde Bilişim Teknolojilerini etkin bir biçimde kullanması beklenmektedir (Doyle, 1994). Bu noktada bilgi toplumunun bireylerin bilişim teknolojileri okuryazarı olmalarını gerekli kıldığı söylenebilir (Dursun, \& Çuhadar, 2009). Burada ifade edilen bilişim teknolojileri okuryazarlığının hangi becerileri içermesi gerektiğine ilişkin olarak çeşitli standartlar geliştirilmiştir. Bunlardan biri öğrenme öğretme ortamlarında teknoloji kullanımıyla ilgili olarak öğrenen ve öğretmenlerin sahip olmaları gereken becerilerin neler olması gerektiğiyle ilgili standartlar geliştiren ISTE (International Society for Technology in Education) kuruluşudur (ISTE, 2016). ISTE standartları incelendiğinde öğrenenlerin bilişim teknolojileri okuryazarlık düzeyleri sadece belirli araçları kullanma becerilerini içermektedir. ISTE standartlarına göre öğrenenler dijital vatandaş, bilgiyi yapılandıran, yenilikçi bir tasarımcı, bilgi işlemsel düşünmeye sahip, yaratıcı iletişimci, global işbirlikçi ve öğrenme öğretme sürecinde yetkili bir öğrenen olmasını içermektedir (ISTE, 2016). Bu ihtiyaçlara yönelik olarak ülkemizde öğrencilerin bilişim teknolojileri uygulamaları ile daha erken yaşlarda tanışmalarını ve gerekli yeterlilikleri edinmelerini sağlamak için ortaokul 5 . ve 6 . sınıflarda Bilişim Teknolojileri ve Yazılım dersi zorunlu hale getirilmiştir. Ancak bazı okullarda 4+4+4 sisteminde okulların dönüşümü ve FATiH projesi uygulamaları sırasında Bilişim Teknolojileri sınıfları kaldırılmış ya da donanımsal olarak güncelliğini yitirmiştir. Bunun neticesinde birçok okulda zorunlu Bilişim Teknolojileri ve Yazılım dersi imkânlardan yoksun işlenmektedir. Yaşanan bu yoksunlukların çeşitli problemlere yol açtığı söylenebilir. Buradan hareketle bu çalışmada Bilişm Teknolojileri ve Yazılım dersinin işlenişinişini ve bu süreçte karşılaşılan problemlerin neler olduğunu belirlemek bu çalışmanın odağını oluşturmaktadır.

\subsection{Türkiye'de Bilişim Teknolojileri Dersine ilişkin Mevcut Durum}

Bilişim Teknolojileri ve Yazılım dersi 1998 yılında açılan Bilgisayar ve Öğretim Teknolojileri Eğitimi (BÖTE) bölümünden mezun öğretmenler tarafından okutulmaktadır. Bilişim Teknolojileri ve Yazııım dersinin mevcut durumunu değerlendirirken öncelikle Bilişim Teknolojileri öğretmenlerine gereken önemin verilmesi ve okullarda bu öğretmenlerin potansiyellerinin etkin şekilde değerlendirilmesi gerekir. Bu durum var olan BT sınıflarının bütün derslerde etkin kullanımı ve özellikle Bilişim Teknolojileri dersinin geleceğine olumlu şekilde yön verecektir.

Ülkemizde 2007 yılından önce bilgisayar dersi olarak adlandırılan bilişim teknolojileri ve yazılım dersi Temel Eğitim Genel Müdürlüğünün 08/05/2013 tarihli ve 886487 sayılı teklif yazısı üzerine illköğretim Kurumları Haftalık Ders Çizelgesi ortaokul kısmında 5. ve 6. sınıflarda 
seçmeli ders statüsünden zorunlu ders statüsüne alınmıştır (Talim ve Terbiye Kurulu Başkanlığı, 2013).

Ancak bilişim teknolojileri ve yazılım dersinin ders saati ve okutulduğu sınıflar üzerine birçok değişiklik yapılmıştır. 2006 yılında hazırlanan ve uygulanan öğretim programına göre bilişim teknolojileri dersinin haftalık ders saati birinci sınıftan sekizinci sınıfa kadar bir ders saati yapılmıştır. Basamaklı sisteme göre ders içeriği hazırlanmış ve öğrencilerin seviyesine göre basamak seçimi yapılmasına olanak tanınmıştır.

Talim ve Terbiye Kurulu Başkanlığının 04.06.2007 tarih ve 111 sayılı kararıyla bilişim teknolojileri dersinin 4. ve 5. Sınıflarda 2007-2008 öğretim yılından itibaren haftalık ders saati 2 olmuştur (Talim ve Terbiye Kurulu Başkanlığı, 2007). Fakat 20.07.2010 tarihinde alınan karar ile bilişim teknolojileri dersi ilkokuldan tamamen kaldırılmıştır. Bu tarihten sonra bilişim teknolojileri dersi sadece ortaokullarda haftada 1 saat seçmeli bir ders olarak okutulmaya başlanmıştır. Ayrıca bu dersin notla değerlendirilmesi uygulanmasına son verilmiştir (Talim ve Terbiye Kurulu Başkanlığı, 2010). Son duruma bakıldığında bilişim teknolojileri ve yazılım dersinin ortaokulların 5 ve 6 . sınıflarında haftada 2 saat olmak üzere zorunlu iken, 7 ve 8 . sınıflarda da yine haftada 2 saat olmak üzere seçmeli dersler kapsamında olduğu görülmektedir.

Bilişim teknolojileri ve yazılım dersinin saati ve seçmeli/zorunlu olma durumuyla ilgili birçok değişiklik yapılırken dersin içeriği ve işleniş̧iyle ilgili çalışmaların olmaması kritik bir noktadır. Bilişim teknolojileri ve yazılım dersinin "oyun oynama dersi" gibi algılara dayandırılan zaman zaman uygulanan dersin saatini azaltma, seçmeli yapma ya da belli kademelerden kaldırma uygulamalarından hareketle bilişim teknolojileri ve yazılım dersinin özüne yönelik çalışmalar yapılmadan bu tür uygulamaların gerçekleştirildiğini göstermektedir. Öte yandan alanyazında bilişim teknolojileri dersinin öğretimine ve hatta bilişim teknolojileri sınıfı olmayan okullarda bilişim teknolojisi ve yazılım derslerinin işlenişine dair araştırmaların olmaması dikkat çekicidir (Phelps, Hase, \& Ellis, 2005; Erdoğan vd., 2010; Sert, 2010).

\subsection{Bilişim Teknolojileri Dersinin İşlenişine Yönelik Yapılmış Araştırmalar}

Alanyazın incelendiğinde bilişim teknolojileri ve yazılım dersi durumunun değişkenliğinin alanyazındaki çalışmaların içeriğine yansımadığı söylenebilir (Erdoğan vd., 2010). Ayrıca alanyazında bilişim teknolojisi derslerinin işlenişini konu alan çalışmaların azlığı dikkat çekicidir (Akbıyık, \& Seferoğlu, 2012). Akbıyık ve Seferoğlu (2012) çalışmalarında bilişim teknolojileri dersinin farkıı bölgelerde nasıl işlendiği ve etkililiğiyle ilgili durumu ortaya çıkarmak için bir araştırma gerçekleştirmişlerdir. Bu araştırmada bilişim teknolojileri öğretmenlerine göre materyal olarak en çok ders kitabı kullanılmakta, yazılımların öğretiminde gösterip yaptırma ve yazılı yönergeler izlenmektedir. Ayrıca bilişim teknolojileri öğretmenleri dersin süresinin azlığından ötürü Milli Eğitim Bakanlığının öğretim programını tamamlayamadıklarını belirtmişlerdir.

Gerekçelerini net olarak bilmediğimiz çeşitli nedenlerden ötürü bu dersin işlenişinde olmazsa olmaz olan bilişim teknoloji laboratuvarlarının donanımsal olarak güncelliklerini kaybettikleri ya da sayısal olarak donanım problemleri yaşandığı görülmektedir. Bu durum bilişim teknolojileri ve yazılım dersinin işlenişinin olumsuz yönde etkilenmesine sebep olduğu söylenebilir. Bu ve bunun gibi bilişim teknolojileri ve yazılım dersinin işlenişinde karşılaşılan zorluk ve problemlerin neler olduğuna yönelik olarak alan yazında çok az sayıda çalışma vardır (Akbıyık, \& Seferoğlu, 2012). Öte yandan bilişim teknolojileri öğretmenlerinin ve öğretmen adaylarının meslek içi karşılaştıkları sorunları ele alan ve öğretim programını inceleyen bazı çalışmalara rastlanmaktadır (Altun, \& Ateş, 2008; Dirisağlık, \& Kabakçı, 2009; Gülcü, Aydın, \& Aydın, 2013; Karal, Reisoğlu, \& Günaydın, 2010; Seferoğlu, 2008; Tanrıöğen, \& Özel, 2011). 
Ancak yapılan çalışmalar bilişim teknolojileri dersiyle ilgili son durumu yansıtmadığı için içeriğinden bahsedilmemiştir.

\subsection{Araştırmanın Amacı}

Bu çalışmanın amacı FATiH projesi uygulamalarının yansımaları doğrultusunda ortaokul 5. ve 6. sınıflarda zorunlu olarak verilen bilişim teknolojileri ve yazııım dersinin okullarda nasıl işlendiğini irdelemek ve bu derste yaşanan problemleri belirlemektir. Bu amaç doğrultusunda MEB'e bağlı okullarda görev yapan bilişim teknolojileri öğretmenlerinin görüşlerine başvurulmuştur. Çalışma kapsamında alt problemler şu şekildedir:

1. Ortaokullarda bilişim teknolojileri dersinin öğretimi nasıl yapılmaktadır?

- Dersinin işlenişinde kullanılan yöntem ve teknikler nelerdir?

- Dersinin işlenişinde kullanılan araç ve gereçler nelerdir?

- Dersinin işlenişinde kullanılan değerlendirme yöntemleri nelerdir?

2. Bilişim teknolojileri öğretmenlerinin karşılaştığı problemler nelerdir?

3. Bilişim teknolojileri öğretmenlerinin karşılaştığı problemlere çözüm önerileri nelerdir?

- Öğrenme ortamından kaynaklanan problemlere çözüm önerileri nelerdir?

- Öğretim programı kaynaklı problemlere çözüm önerileri nelerdir?

- Bireysel mesleki yeterliliklerle ilgili problemlere çözüm önerileri nelerdir?

- Okul yönetiminden kaynaklanan problemlere çözüm önerileri nelerdir?

\subsection{Araştırmanın Önemi}

Bilişim teknolojilerindeki gelişmeler günlük hayatımızın aşamasında hissedilmektedir.

Hatta bu gelişmeler hayatımıza etkilerinin yanı sıra çağımızın "bilişim çağı" olarak nitelenmesine vesile olmuştur. Hayatımızın vazgeçilmez parçası haline gelen söz konusu bu değişimlere ayak uydurmak için bilişim teknolojilerini amacına uygun kullanabilme yetkinliğine sahip bireylerin yetiştirilmesi zorunluluk haline gelmiştir (Dirisağlık, \& Kabakçı, 2009; Tanrıöğen, \& Özel, 2011). Bu konuda en büyük katkıyı ortaokullarda zorunlu olan bilişim teknolojileri dersinin yapacağı düşünülmektedir. Çünkü MEB tarafından bilişim teknolojileri dersi K-12'de zorunlu olarak sadece 5. ve 6. sınıflarda verilmektedir. Bu çalışma ortaokullarda bilişim teknolojileri dersinin işlenişine ışık tutması açısından önemli görülmektedir.

\section{YÖNTEM}

Araştırmalarda hem nicel hem de nitel yöntemlerin birlikte kullanılması karma yöntem yaklaşımı olarak tanımlanır (Yıldırım, \& Şimşek, 2005). Karma yaklaşımda nicel yöntem ile daha çok katılımcıya ulaşıııken, nitel yöntemlerle ele alınan konunun daha derinlemesine işlenmesine olanak tanımaktadır. Ayrıca nitel araştırma, araştırma yapılan ortamın ve durumun doğal ve canlı sürecini bozmadan sürece dâhil olmayı sağlar (Yıldırım, \& Şimşek, 2005). Karma yöntem sayesinde nicel yöntemle elde edilen sayısal veriler yorumlanır ve derinlemesine analiz edilebilir. Öte yandan karma yöntem veri ve araç çeşitlemesi gibi unsurları içererek geçerlik ve güvenirlik için de araştırma açısından önemli fırsatlar sağlar.

Bu çalışmada hem nicel hem de nitel boyutları içeren açıklayıcı karma yöntem kullanılmıştır. Araştırma, FATiH projesi ile teknoloji ile zenginleştirilen okullarda bilişim teknolojileri öğretmenlerinin dersin işlenişi açısından uygulamalarını araştırmacı tarafından hazırlanan anket aracılı̆̆ıyla taramayı amaçlayarak nicel yönteme; bu durumla ilgili faktörleri ve bu durumun bilişim teknolojileri öğretmenlerini nasıl etkilediğini açık uçlu görüşme sorularıyla belirlemek amacıyla nitel yönteme başvurulmuştur. 


\section{1. Çalışma Grubu}

FATiH projesi okullarında bilişim teknolojileri 5. ve 6. sınıfların dersine giren 50 tane bilişim teknolojileri öğretmeninin görüşü alınmıştır. Araştırma 2015-2016 eğitim-öğretim yılı güz döneminde Ankara'da gerçekleştirilmiştir.

Tablo 1

Katılımcıların Demografik Özellikleri

\begin{tabular}{llcc}
\hline Değişkenler & & $f$ & $\%$ \\
\hline \multirow{2}{*}{ Cinsiyet } & Kadın & 19 & 38 \\
& Erkek & 31 & 62 \\
\hline \multirow{2}{*}{ Yaş } & $20-30$ & 34 & 68 \\
& $31-40$ & 16 & 32 \\
\hline \multirow{3}{*}{ Hizmet Süresi } & $1-5$ yıl & 26 & 52 \\
& $6-10$ yıl & 17 & 34 \\
& $11-15$ yıl & 7 & 14 \\
\hline \multirow{3}{*}{ Eğitim Durumu } & Lisans & 41 & 82 \\
& Yüksek Lisans & 7 & 14 \\
\hline \multirow{2}{*}{ Sosyo-ekonomik } & Doktora & 2 & 4 \\
Durum & Alt & 24 & 48 \\
& Orta & 23 & 46 \\
\hline
\end{tabular}

Çalışma grubuna ait demografik özellikler incelendiğinde ortaokullarda görev yapan bilişim teknolojileri öğretmenlerinin \%38'inin kadın \%62'sinin erkek olduğu görülmektedir. Amaçlı örnekleme tekniğiyle seçilen çalışma grubunun büyük bölümü (\%68) 20-30 yaş aralığındadır. Katılımcıların \%52'sinin mesleki kıdemi 1-5 yıl iken sadece $\% 6$ 'sı yüksek sosyoekonomik düzeyli bir bölgede çalışmaktadır.

\subsection{Veri Toplama Aracı}

Bu çalışmada veri toplama aracı olarak araştırmacılar tarafından geliştirilen "demografik bilgi anketi" ve "bilişim teknolojileri dersi işlenişi anketi" ve "bilişim teknolojileri dersinin işleyişinde karşılaşılan engeller ve öneriler" adlı yarı yapılandırılmış görüşme formu kullanılmıştır. Bilişim teknolojileri öğretmenlerine bilişim teknolojileri dersi işlenişi anketi ve kişisel bilgileri toplamak amacıyla demografik bilgi anketi kullanılmıştır.

Demografik bilgi anketinde çalışma grubunun demografik özelliklerini belirlemek amacıyla 8 soru sorulmuştur. Bu ankette çalışma grubunun "cinsiyet, yaş, hizmet süresi, eğitim durumu ve görev yeri"yle ilgili maddeler yer almaktadır.

Bilişim Teknolojileri dersi işlenişi anketinde ise bilişim teknolojileri öğretmenlerinin bilişim teknolojileri dersinin işlenişiyle ilgili görüşlerini toplamak amacıyla toplam 40 maddeye yer verilmiştir. Bilişim teknolojileri dersi işlenişi anketinde soru maddeleri (1-Hiçbir zaman, 2Nadiren, 3-Bazen, 4-Sıklıkla, 5-Her zaman) ve (1-Kesinlikle Katılmıyorum, 2-Katılmıyorum, 3Kararsızım, 4-Katılıyorum, 5-Kesinlikle Katılıyorum) şeklinde beşli likert türünde derecelendirme yapılarak yanıtlanması istenmiştir.

"Bilişim teknolojileri dersinin işleyişinde karşılaşılan engeller ve öneriler" yarı yapılandırılmış görüşme formunda öğretmenlerin derse ilgili planları, beklentileri, gerçekleştirebilip gerçekleştiremediği uygulamalar, karşılaştıkları sorunlar ve çözümlerle ilgili 5 madde bulunmaktadır.

Veri toplama araçları geliştirilirken belirlenen konuyla ilgili alanyazın incelenerek aday maddeler belirlenmiştir. Maddeler belirlenirken Aykaç (2011) tarafından yapılan çalışmadan yararlanılmıştır. Bunun yanı sıra bilişim teknolojileri öğretmeni olarak görev yapan bilişim 
teknolojileri öğretmenlerinin görüşlerine de başvurulmuştur. Anketin asıl uygulanma sürecinden önce 2 kişiyle ön uygulama gerçekleştirilmiştir. Bu uygulamalardan elde edilen görüş ve öneriler ışığında sorulara eklemeler ve maddelerde bazı anlamsal/yapısal değişiklikler yapılmıştır.

\subsection{Veri Toplama Süreci}

5. ve 6. sınıfların bilişim teknolojileri dersine giren bilişim teknolojileri öğretmenlerine araştırmacılar tarafından geliştirilen anket ve görüşme formu uygulanmıştır. Veri toplama araçları doldurulmadan önce bir yönerge aracılığıyla çalışmayla ilgili gerekli bilgilendirme yapılımışır.

\subsection{Veri Analizi}

Bu araştırma kapsamında veri toplama araçları aracılığıyla toplanan nitel veriler Nvivo 11 programı ile araştırmacılar tarafından ayrı ayrı kodlanmıştır. Araştırmacıların içerik analizi sonucu yapılan kodlamanın kodlarının eşleme oranı \%90,102'dir. Kodlayıcı tutarlılı̆ı ve ortaya konulan kod şemasının geçerliliği ve güvenirliğini sağlamak için kodların içerdiği anlam hakkında irdelenmiş ve \%100 fikir birliği sağlanmıştır. Farklı fikirlerin ortaya çıktığı kodlamalarda ortak karar verilmiştir. Nicel verilerin analizlerinde frekans, yüzde ve aritmetik ortalamayı hesaplamak için SPSS 18 programı kullanılmıştır.

\section{BULGULAR}

Bulgular, araştırmanın alt problemlerinin sırasına göre sunulmuştur.

3.1. Ortaokullarda Yöntem/Teknikler, Araç/Gereçler, Değerlendirme Yöntemleri Açısından Bilişim Teknolojileri Dersinin Öğretimi

Bilişim teknolojileri öğretmenlerinin derslerinde hangi yöntem ve tekniklere ağırlık verdiğini belirlemek amacıyla ilgili veriler Tablo 2'de verilmektedir.

Tablo 2

BT Dersinin Işlenişinde Kullanılan Yöntem ve Teknikler

\begin{tabular}{|c|c|c|c|c|c|c|c|}
\hline Yöntem ve Teknikler & & 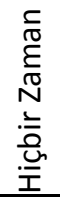 & 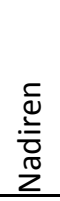 & $\begin{array}{l}\text { D } \\
\mathbb{N} \\
\mathbb{D} \\
\infty\end{array}$ & $\begin{array}{l}\stackrel{0}{\forall} \\
\overline{\bar{n}}\end{array}$ & $\begin{array}{l}\frac{1}{\pi} \\
\stackrel{5}{E} \\
\frac{N}{N} \\
\frac{1}{d} \\
\text { I }\end{array}$ & $\begin{array}{l}\frac{E}{\pi} \\
\frac{0}{0} \\
\end{array}$ \\
\hline \multirow{2}{*}{ 1. Anlatma } & $f$ & 0 & 2 & 4 & 18 & 26 & 50 \\
\hline & $\%$ & 0 & 4 & 8 & 36 & 52 & 100 \\
\hline \multirow{2}{*}{ 2. Gösterme/ Yaptırma } & $f$ & 0 & 15 & 4 & 7 & 24 & 50 \\
\hline & $\%$ & 0 & 30 & 8 & 14 & 48 & 100 \\
\hline \multirow{2}{*}{ 3. Soru cevap } & $f$ & 0 & 3 & 8 & 32 & 7 & 50 \\
\hline & $\%$ & 0 & 6 & 16 & 64 & 14 & 100 \\
\hline \multirow{2}{*}{ 4. Proje çalışması } & $f$ & 13 & 24 & 10 & 2 & 1 & 50 \\
\hline & $\%$ & 26 & 48 & 20 & 4 & 2 & 100 \\
\hline \multirow{2}{*}{ 5. Tartışma } & $f$ & 4 & 13 & 10 & 18 & 5 & 50 \\
\hline & $\%$ & 8 & 26 & 20 & 36 & 10 & 100 \\
\hline \multirow{2}{*}{ 6. Beyin Fırtınası } & $f$ & 5 & 14 & 16 & 11 & 4 & 50 \\
\hline & $\%$ & 10 & 28 & 32 & 22 & 8 & 100 \\
\hline \multirow{2}{*}{ 7. Şapka } & $f$ & 29 & 15 & 5 & 1 & 0 & 50 \\
\hline & $\%$ & 58 & 30 & 10 & 2 & 0 & 100 \\
\hline
\end{tabular}


Tablo 2'ye göre anlatma ve gösterip yaptırma yönteminin bilişim teknolojileri öğretmenlerince en sık kullanılan yöntemler olduğu görülmektedir. Bu durum bilişim teknolojileri öğretiminde öğretmen odaklı geleneksel bir anlayışın sürdüğüne işaret olarak gösterilebilir. Öte yandan 6 şapka ve proje çalışması yöntemlerinin ise diğer yöntemlere göre daha az sıkıkla kullanıldığı bulunmuştur. Ayrıca 6 şapka ve proje yöntemini hiç kullanmadığını belirten öğretmen sayısı sırasıyla 29 ve 13'tür. Bu durumun öğrencinin farklı boyutlarda düşünerek bir ürün ortaya koymasına bilişim teknolojileri dersi kapsamında yer verilmediğinin göstergesi olarak yorumlanabilir.

Açık uçlu sorularla öğretmenlerden alınan görüşlere bakıldığında bilişim teknolojileri dersinin uygulama tabanlı bir ders olduğu ve gösterme yaptırma yönteminin ise dersin doğasına uygun en kullanışlı yöntem olduğu görülmektedir. Bu konuda bazı öğretmenlerin görüşleri şöyledir:

Dersi uygulama ağırlıklı yaparak öğrencilerin performansa dayalı becerilerini görürüm. Öğrencilerin temel programları öğrenmelerini ve bu programları diğer dersleri için kullanmalarına olanak sağlarım [K17].

Bol uygulamalı dersler planlar, ögrencilere bol bol uygulama yaptırır daha somut örnekler gösteririm. Ders bunu gerektiriyor ama imkân araç gereç yetersizliği buna yeterince imkan sağlanmıyor [K9].

FATiH projesiyle okullarda tablet, akıllı tahta ve ağ alt yapısı sağlandığı için, tabi buna kalabalık öğrenciden dolayı sınıf sıkıntısı da eklenince bilişim sınıfımız kapandı. Ancak tabletler lise düzeyinde dağıtıldı henüz okullarımızda yok. Bu nedenle havuz olamadan yüzmeyi öğrenmek ne kadar yeterliyse BT sınıfı olmadan BT dersini öğretmek o kadar yeterli oluyor. [K22].

Öğretmen görüşlerine göre bilişim teknolojileri sınıfının olmaması veya kaldııılmasıyla bilişim teknolojileri dersi hedeflerinin yerine getirilmesi için çeşitli yöntem ve tekniklerin etkisiz kalacağı söylenebilir.

Bilişim teknolojileri öğretmenlerinin derslerinde hangi araç ve gereçleri daha sık kullandığı tespit etmek amacıyla ilgili veriler Tablo 3'te verilmektedir.

Tablo 3

BT Dersinin Işlenişinde Kullanılan Araç ve Gereçler

\begin{tabular}{|c|c|c|c|c|c|c|c|}
\hline Maddeler & & 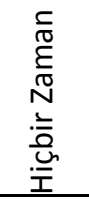 & 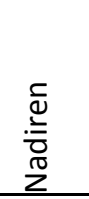 & $\begin{array}{l}\widetilde{D} \\
\mathbb{N} \\
\mathbb{D} \\
\end{array}$ & $\begin{array}{l}\frac{\pi}{6} \\
\stackrel{5}{n}\end{array}$ & 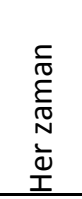 & $\begin{array}{l}\varepsilon \\
\frac{\varepsilon}{\pi} \\
\frac{0}{0} \\
\stackrel{0}{\circ}\end{array}$ \\
\hline \multirow{2}{*}{ 1. Ders Kitabı } & $f$ & 40 & 4 & 3 & 1 & 2 & 50 \\
\hline & $\%$ & 80.0 & 8.0 & 6.0 & 2.0 & 4.0 & 100 \\
\hline \multirow{2}{*}{ 2. Çalışma yaprakları } & $f$ & 16 & 9 & 15 & 6 & 4 & 50 \\
\hline & $\%$ & 32.0 & 18.0 & 30.0 & 12.0 & 8.0 & 100 \\
\hline \multirow{2}{*}{ 3. Projeksiyon } & $f$ & 17 & 3 & 7 & 13 & 10 & 50 \\
\hline & $\%$ & 34.0 & 6.0 & 14.0 & 26.0 & 20.0 & 100 \\
\hline \multirow{2}{*}{ 4. Etkileşimli tahta } & $f$ & 27 & 1 & 5 & 6 & 11 & 50 \\
\hline & $\%$ & 54.0 & 2.0 & 10.0 & 12.0 & 22.0 & 100 \\
\hline \multirow{2}{*}{ 5. Web siteleri } & $f$ & 21 & 8 & 10 & 7 & 4 & 50 \\
\hline & $\%$ & 42.0 & 16.0 & 20.0 & 14.0 & 8.0 & 100 \\
\hline \multirow{2}{*}{ 6. Animasyonlar } & $f$ & 17 & 6 & 14 & 10 & 3 & 50 \\
\hline & $\%$ & 34.0 & 12.0 & 28.0 & 20.0 & 6.0 & 100 \\
\hline
\end{tabular}


Ortaokullarda Bilişim Teknolojileri ve Yazılım Dersinin İşlenişi, Yaşanan Problemler ve Çözüm Önerileri: Öğretmen Görüşleri

Şefika Şule ERÇETiN - Aykut DURAK

\begin{tabular}{llcccccc}
\hline 7. Dersle ilgili sunumlar & $\mathrm{f}$ & 11 & 4 & 9 & 13 & 13 & 50 \\
& $\%$ & 22.0 & 8.0 & 18.0 & 26.0 & 26.0 & 100 \\
8. Kelime işlemci (Word) & $\mathrm{f}$ & 16 & 8 & 9 & 13 & 4 & 50 \\
& $\%$ & 32.0 & 16.0 & 18.0 & 26.0 & 8.0 & 100 \\
9. Elektronik Tablolama (Excel) & $\mathrm{f}$ & 17 & 13 & 8 & 9 & 3 & 50 \\
& $\%$ & 34.0 & 26.0 & 16.0 & 18.0 & 6.0 & 100 \\
10. Sunu Programı (Powerpoint) & $\mathrm{f}$ & 16 & 7 & 5 & 11 & 11 & 50 \\
11. Masaüstü Yayıncılık Programı & $\mathrm{f}$ & 32.0 & 14.0 & 10.0 & 22.0 & 22.0 & 100 \\
(Publisher) & $\%$ & 56.0 & 22.0 & 12.0 & 8.0 & 2.0 & 100 \\
12. Veri Tabanı Programı (Access) & $\mathrm{f}$ & 35 & 8 & 5 & 1 & 1 & 50 \\
& $\%$ & 70.0 & 16.0 & 10.0 & 2.0 & 2.0 & 100 \\
\hline
\end{tabular}

Tablo 3'e göre bilişim teknolojileri öğretmenlerinin derslerinde en sık kullandığı araç, gerecin dersle ilgili sunumlar olduğu anlaşılmaktadır $(f=39)$. Dersle ilgili sunumların yanı sıra öğretmenlerin projeksiyonu da derslerinde sıklıkla kullandığı görülmektedir ( $f=33$ ). Öte yandan ders kitabı ve veri tabanı programını öğretmenlerin derslerinde neredeyse hiçbir zaman kullanmadığı bulunmuştur $(f=40 ; f=35)$. Bilişim teknolojileri öğretmenlerinin araç gereç ve materyal kullanımıyla ilgili görüşleri ise şu şekildedir.

Bilişim Teknolojileri ve yazılım uygulamada zorunlu ders olduktan sonra piyasada öğrenci kitabı olmadığı gibi öğretmen kılavuz kitabı da bulunmamaktadır. Bu bağlamda ders kitabı kullanmamızı beklemek anlamsız oluyor [K21].

Office programlarını öğretiyordum. Ancak bilişim konulu AB projeleri hazırlama hayalim var. Ama artık Scratch, sketchup programlarını kullanımını ve uygulamasını öğreniyoruz, çok zevkli ve faydalı [K17]..

Bilişim yeterliliklerini kazandırmak için kelime işlemci programların kullanımı ile etkili bir öğrenme gerçekleşiyor. [K38].

Ders kitabi, çalışma kitabı materyali olması lazım...[K25].

Bilişim teknolojileri öğretmenlerinin açık uçlu sorularda verdiği cevaplara göre derslerinde ders kitabı gibi önemli görülen bir araç, gerecin eksikliğini hissettikleri görülmektedir. Ayrıca öğretmenler bilgisayar programlama programlarının da derslerde kullanmanın faydalı olduğunu belirtmektedir.

Bilişim teknolojileri öğretmenlerinin derslerinde hangi değerlendirme yöntemlerine başvurduğunu ortaya koymak için ilgili veriler Tablo 4'te sunulmuştur.

Tablo 4

BT Dersinin İşlenişinde Kullanılan Değerlendirme Yöntemleri

\begin{tabular}{|c|c|c|c|c|c|c|c|}
\hline Maddeler & & 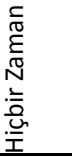 & $\begin{array}{l}\frac{0}{d} \\
\frac{\pi}{2} \\
\frac{\pi}{2}\end{array}$ & 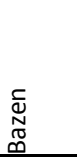 & 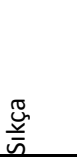 & $\begin{array}{l}\frac{1}{0} \\
\text { ह } \\
\text { N } \\
\text { N } \\
\frac{d}{I}\end{array}$ & $\begin{array}{l}\frac{\varepsilon}{\pi} \\
\frac{0}{0} \\
\text { 임 }\end{array}$ \\
\hline \multirow{2}{*}{ 1. Klasik sınavlar } & $f$ & 2 & 3 & 4 & 10 & 31 & 50 \\
\hline & $\%$ & 4 & 6 & 8 & 20 & 62 & 100 \\
\hline \multirow{2}{*}{ 2. Akran değerlendirmesi } & f & 33 & 9 & 7 & 1 & 0 & 50 \\
\hline & $\%$ & 66 & 18 & 14 & 2 & 0 & 100 \\
\hline \multirow{2}{*}{ 3. Öz değerlendirme } & $f$ & 32 & 7 & 9 & 1 & 1 & 50 \\
\hline & $\%$ & 64 & 14 & 18 & 2 & 2 & 100 \\
\hline \multirow{2}{*}{ 4. Performans değerlendirmesi } & $f$ & 21 & 7 & 15 & 4 & 3 & 50 \\
\hline & $\%$ & 42 & 14 & 30 & 8 & 6 & 100 \\
\hline \multirow{2}{*}{ 5. Portfolyo } & $f$ & 31 & 11 & 6 & 1 & 1 & 50 \\
\hline & $\%$ & 62 & 22 & 12 & 2 & 2 & 100 \\
\hline
\end{tabular}


Tablo 4'e göre bilişim teknolojileri öğretmenlerinin derslerinde en sık klasik sınavlarla değerlendirme yöntemlerini kullanmaktadır. Bu değerlendirme yönteminin diğer yöntemlere göre çok daha sık kullanıldığı anlaşılmaktadır $(f=48)$. Öğretmenlerin derslerinde en az kullandığı değerlendirme yönteminin ise akran değerlendirme olduğu görülmektedir $(f=7)$. Değerlendirme yöntemlerine ilişkin öğretmen görüşlerine bakıldığında ise öğretmenler neden klasik sınavlar dışındaki yöntemlere başvurmadığı açıkça görülmektedir.

Daha az mevcutlu ve donanımı olan sınıflarım olsaydı uygulamaya yönelik dersler işlerdim. Değerlendirmeyi klasik sınav yerine daha çok uygulamaya ve bireyselliğe yönelik uygulardım. Daha fazla etkinlik, uygulama, proje ve performans çalışmaları yapar ve yaptırırdım [K30].

Ders anlatım yöntemleri, uygulamalar, değerlendirmeler daha çok sistemin genel isteklerine bağlı değişiyor [K28].

\subsection{Ortaokullarda Görev Yapan Bilişim Teknolojileri Öğretmenlerinin Karşılaştığı}

\section{Problemler}

Ortaokullarda görev yapan bilişim teknolojileri öğretmenlerine göre derslerinde en sık karşılaştıkları problemleri tespit etmek için ilgili veriler Tablo 5'te sunulmuştur.

Tablo 5

BT Öğretmenlerinin Karşılaştığı Problemler

\begin{tabular}{|c|c|c|c|c|c|c|c|}
\hline Maddeler & & 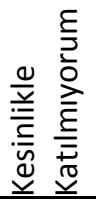 & 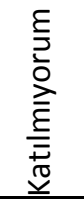 & $\begin{array}{l}\frac{E}{N} \\
\frac{N}{\omega} \\
\frac{\pi}{\sqrt{0}} \\
\frac{\underline{x}}{4}\end{array}$ & 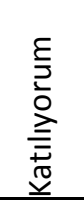 & 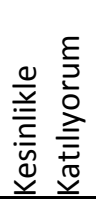 & $\begin{array}{l}\frac{\varepsilon}{\pi} \\
\frac{0}{0} \\
\end{array}$ \\
\hline $\begin{array}{l}1 \text { Talim terbiye kurulunca belirlenen } \\
\text { öğretim programının yetersiz }\end{array}$ & $f$ & 0 & 1 & 5 & 17 & 27 & 50 \\
\hline olması & $\%$ & 0 & 2.0 & 10.0 & 34.0 & 54.0 & 100 \\
\hline 2 Ders içeriğinin belli olmaması & $\begin{array}{l}f \\
\%\end{array}$ & $\begin{array}{c}2 \\
4.0\end{array}$ & $\begin{array}{c}2 \\
4.0\end{array}$ & $\begin{array}{c}6 \\
12.0\end{array}$ & $\begin{array}{c}8 \\
16.0\end{array}$ & $\begin{array}{c}32 \\
64.0\end{array}$ & $\begin{array}{c}50 \\
100\end{array}$ \\
\hline 3 Ders ve çalışma kitaplarının & $f$ & 1 & 0 & 1 & 6 & 42 & 50 \\
\hline olmaması & $\%$ & 2.0 & 0 & 2.0 & 12.0 & 84.0 & 100 \\
\hline 4 Sınıflardaki bilişim teknolojileri & $f$ & 2 & 3 & 6 & 9 & 30 & 50 \\
\hline elektrik altyapısının yetersiz olması & $\%$ & 4.0 & 6.0 & 12.0 & 18.0 & 60.0 & 100 \\
\hline $\begin{array}{l}5 \text { Sınıflardaki BT dersiyle ilgili } \\
\text { materyallerin yetersiz }\end{array}$ & $f$ & 0 & .0 & 2 & 10 & 38 & 50 \\
\hline olması/olmaması & $\%$ & 0 & .0 & 4.0 & 20.0 & 76.0 & 100 \\
\hline $\begin{array}{l}6 \text { Öğrencilerin } \\
\text { seviyelerini/farklılıkları baz alan bir }\end{array}$ & $f$ & 5 & 6 & 4 & 8 & 27 & 50 \\
\hline öğretim programı uygulanmaması & $\%$ & 10.0 & 12.0 & 8.0 & 16.0 & 54.0 & 100 \\
\hline 7 Öğrencilerin dersle ilgili konuları & $f$ & 0 & 2 & 4 & 13 & 31 & 50 \\
\hline somutlaştıramaması & $\%$ & .0 & 4.0 & 8.0 & 26.0 & 62.0 & 100 \\
\hline 8 Uygulamaya dayalı etkinliklerin & $f$ & 0 & 2 & 3 & 2 & 43 & 50 \\
\hline gerçekleştirilememesi & $\%$ & 0 & 4.0 & 6.0 & 4.0 & 86.0 & 100 \\
\hline
\end{tabular}


Ortaokullarda Bilişim Teknolojileri ve Yazılım Dersinin İşlenişi, Yaşanan Problemler ve Çözüm Önerileri: Öğretmen Görüşleri

Şefika Şule ERÇETiN - Aykut DURAK

\begin{tabular}{|c|c|c|c|c|c|c|c|}
\hline \multirow{2}{*}{$\begin{array}{l}9 \text { Akıllı tahta e-içeriklerinin yetersiz } \\
\text { olması }\end{array}$} & $f$ & 3 & 3 & 9 & 13 & 22 & 50 \\
\hline & $\%$ & 6.0 & 6.0 & 18.0 & 26.0 & 44.0 & 100 \\
\hline \multirow{2}{*}{$\begin{array}{l}10 \text { internet bağlantısının yavaş } \\
\text { olması/olmaması }\end{array}$} & $f$ & 3 & 1 & 4 & 10 & 32 & 50 \\
\hline & $\%$ & 6.0 & 2.0 & 8.0 & 20.0 & 64.0 & 100 \\
\hline \multirow[t]{2}{*}{11 Sınıfların kalabalık olması } & $f$ & 3 & 6 & 8 & 10 & 23 & 50 \\
\hline & $\%$ & 6.0 & 12.0 & 16.0 & 20.0 & 46.0 & 100 \\
\hline \multirow[t]{2}{*}{12 Ders saatinin yetersiz olması } & $f$ & 2 & 8 & 10 & 13 & 17 & 50 \\
\hline & $\%$ & 4.0 & 16.0 & 20.0 & 26.0 & 34.0 & 100 \\
\hline \multirow{2}{*}{$\begin{array}{l}13 \text { İdarenin derse karşı olumsuz } \\
\text { tutumu }\end{array}$} & $f$ & 2 & 9 & 1 & 16 & 22 & 50 \\
\hline & $\%$ & 4.0 & 18.0 & 2.0 & 32.0 & 44.0 & 100 \\
\hline \multirow{2}{*}{$\begin{array}{l}14 \text { Diğer öğretmenlerin derse karşı } \\
\text { olumsuz tutumu }\end{array}$} & $f$ & 2 & 11 & 6 & 12 & 19 & 50 \\
\hline & $\%$ & 4.0 & 22.0 & 12.0 & 24.0 & 38.0 & 100 \\
\hline \multirow{2}{*}{$\begin{array}{l}15 \text { Öğrencilerin derse karşı olumsuz } \\
\text { tutumu }\end{array}$} & $f$ & 4 & 14 & 10 & 10 & 12 & 50 \\
\hline & $\%$ & 8.0 & 28.0 & 20.0 & 20.0 & 24.0 & 100 \\
\hline \multirow{2}{*}{$\begin{array}{l}16 \text { BT öğretmenlerine ders dışı çok } \\
\text { fazla görev ve sorumluluk verilmesi }\end{array}$} & $f$ & 1 & 1 & 9 & 8 & 31 & 50 \\
\hline & $\%$ & 2.0 & 2.0 & 18.0 & 16.0 & 62.0 & 100 \\
\hline
\end{tabular}

Tablo 5'e bakıldığında bilişim teknolojileri öğretmenlerinin derslerinde en sık karşılaştığı sorunların başında uygulamaya dayalı etkinliklerin gerçekleştirilememesi, sınıflardaki BT dersiyle ilgili materyallerin yetersiz olması/olmaması ve ders-çalışma kitaplarının olmaması sorunudur ( $f=50 ; f=50 ; f=49)$. Öğretmenlere göre en az karşılaşılan sorunun ise teknoloji okuryazarlı̆̆ı farklı öğrencilerin seviyelerine göre bir öğretim programı uygulanmaması olduğu görülmektedir ( $f=35)$.

Açık uçlu sorularda bilişim teknolojileri öğretmenleri yaşadığı sorunlara ilişkin toplanan nitel veriler kodlanmıştır ve elde edilen kodlar Şekil 1'de sunulmuştur.

Şekil 1'e göre en sık gözlenen kodlar "uygulamaya uygun ortam eksikliği", ders kitabının olmaması, uygulama ortamı eksikliklerinin öğrenci tutumuna olumsuz etkisi"dir.

Öğretmenler bu durumla ilgili görüşlerini şöyle dile getirmektedirler:

Kazanımlar, hedefler öğrenci özelliklerine göre değil. Henüz 10-12 yaşlarında olan bu öğrencilerimin internet kafelerde bahis oyunları oynuyor olması gibi sebeplerin hiçbirine maruz kalmaması adına veliler, okul idaresi, milli eğitim ile işbirliği içinde çalışmalı. [K19]. Kesinlikle birçok sorun var. Bilişim teknolojileri yeterlilikleri belirleniyor ama bir vizyon eksikliği var [K17]. 


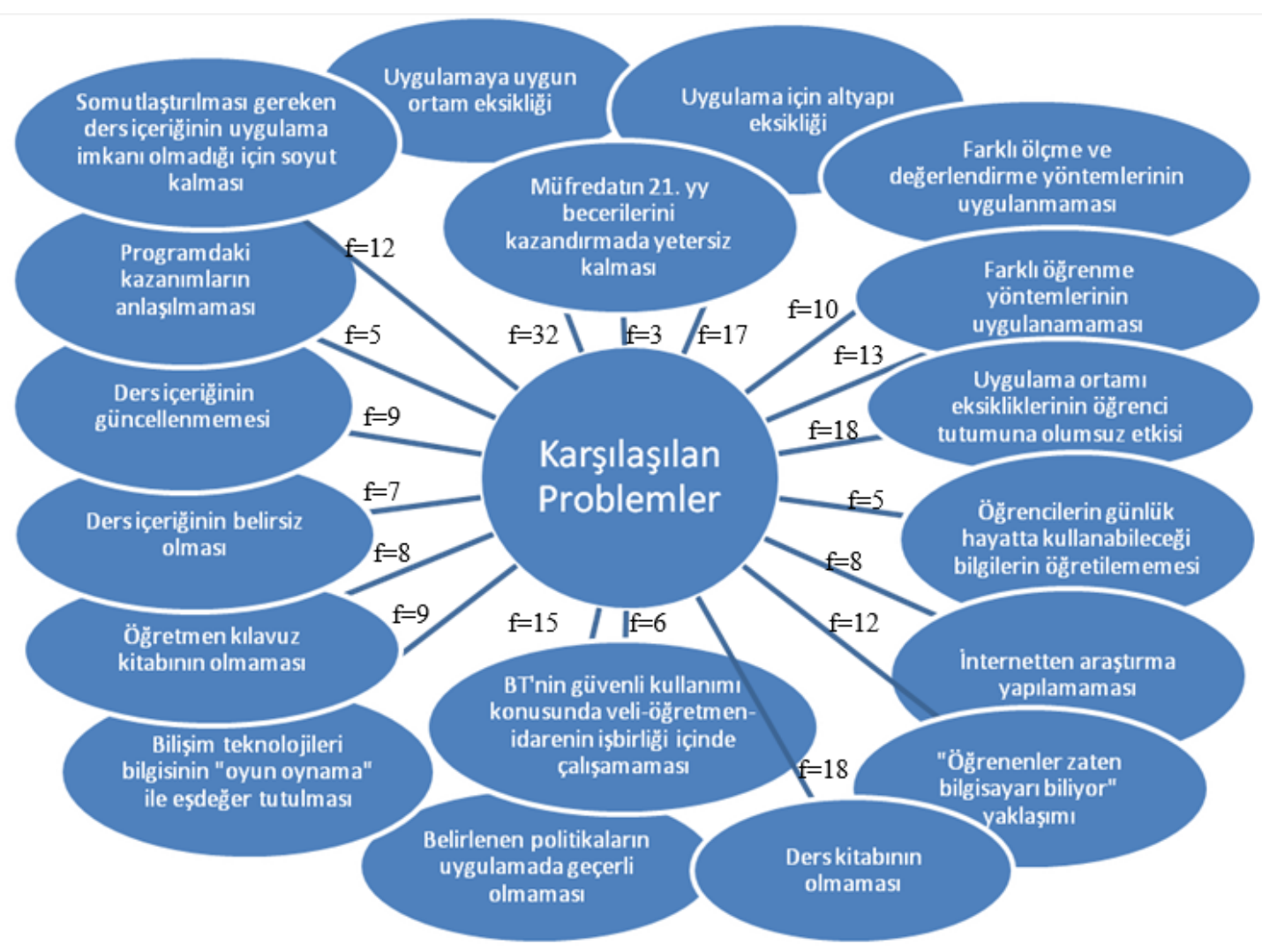

Şekil 1. BT Öğretmenlerinin karşılaştığı problemler

\subsection{Ortaokullarda Görev Yapan Bilişim Teknolojileri Öğretmenlerinin Karşılaştığı Problemlere Çözüm Önerileri}

Ortaokullarda bilişim teknolojileri öğretmenlerine göre derslerinde en sık karşılaştıkları problemlere sundukları çözüm önerileriyle ilgili tema ve kodlar Tablo $6^{\prime}$ da sunulmuştur.

Tablo 6

BT Öğretmenlerinin Karşılaştığı Problemlere Sundukları Çözümler

\begin{tabular}{lll}
\hline Temalar & Kodlar & $\mathbf{f}$ \\
\hline Öğrenme ortamından kaynaklanan & Araç gereç eksiklerinin tamamlanmalı & 10 \\
\cline { 2 - 3 } problemlere çözüm önerileri & $\begin{array}{l}\text { BT sınıflarının belirli aralıklarda } \\
\text { güncellenmeli }\end{array}$ & 7 \\
\cline { 2 - 3 } & Kalabalık sınıflar azaltılmalı & 3 \\
\hline $\begin{array}{l}\text { Öğretim programı kaynaklı problemlere } \\
\text { çözüm önerileri }\end{array}$ & Ders kitabı hazırlanmalı & 8 \\
\cline { 2 - 3 } & Müfredat güncellenmeli & 5 \\
\cline { 2 - 3 } & $\begin{array}{l}\text { Yeterliliklere uygun araç ve etkinlikler } \\
\text { Önerilmeli }\end{array}$ & 2 \\
\hline Bireysel mesleki yeterliliklerle ilgili & Öğretmenlere BT yeterliliği kazandırılmalı & 2 \\
\cline { 2 - 3 } problemlere çözüm önerileri & Idarecilere BT yeterliliği kazandırılmalı & 1 \\
\hline Okul yönetiminden kaynaklanan & BT öğretmenlerinin görev tanımlarını & 4 \\
problemlere çözüm önerileri & anlatılmalı & 2 \\
\cline { 2 - 3 } & İdareye teknik destek sağlanmalı & 2 \\
\hline
\end{tabular}

Tablo 6 incelendiğinde bilişim teknolojileri öğretmenleri karşılaştığı problemlere en sık "öğrenme ortamından kaynaklanan problemlere çözüm önerileri" üreterek çözümün 
sağlanacağını düşünmektedir. Öğrenme ortamıyla ilgili çözümlerde "araç gereç eksiklerinin tamamlanmalı" kodu en sık kodlanan koddur. Kısaca öğretmenler yaşadıkları problemleri karşılaştıkları araç gereç eksiklerinin tamamlanarak çözüleceğini düşünmektedirler. Bu durumla ilgili bilişim teknolojileri öğretmenlerinin görüşleri şöyledir:

Evinde sürekli bilgisayar ve teknolojik aletleri kullanan öğrenci okuldaki bilişim ve yazılım dersinde bilgisayarları ve içeriği görünce dersi önemsemiyor. Dolayısıyla dersin verimi oldukça düşüyor ve hedeflere ulaşmak, yöntem teknik uygulamak imkânsız hale geliyor [K20].

Sınıflar kalabalık!!! Oğlum sus, kızım önüne dön demekten dikkatleri toparlayamıyoruz ki... Dikkati toplarsın dersin ortasında idareci gelir "hocam bi bakar mısınız?" der... Geçmiş olsun ders bitti. Defteri imzaladın yoklamayı aldıysan ne mutlu sana. [K33].

\section{SONUÇ, TARTIŞMA VE ÖNERILER}

$\mathrm{Bu}$ çalışmanın amacı ortaokullarda bilişim teknolojileri dersinin nasıl işlendiğini irdelemek ve bu derste yaşanan problemleri belirlemektir. Bu bölümde elde edilen bulgular tartışılarak, bu tartışmalardan hareketle ulaşılan sonuçlar sunulmuştur. Ayrıca ulaşılan sonuçlardan yola çıkılarak öneriler geliştirilmiştir.

Araştırma kapsamında bilişim teknolojileri öğretmenlerinin en sık kullandığı yöntemlerin anlatma ve gösterip yaprtırma olduğu, en az kullandıkları yöntemlerin ise 6 şapka ve proje çalışması yöntemlerinin olduğu sonucuna ulaşılmıştır. Ders kapsamında kullanılan yöntemlerin genel olarak öğretmen merkezli bir yapıya sahip olduğu söylenebilir. Akbıyık ve Seferoğlu (2012) yaptıkları çalışmada benzer şekilde öğrenme-öğretme faaliyetlerinde katılımcı öğretmenlerin çounluğunun projeksiyon ile anlatım, gösterim yapıp öğrenenlerin uygulama yapmasına yer verdikleri belirtmişlerdir. Bu durumun sebeplerinden bazıları laoratuvarlarda gerekli donanım eksikliği/yetersizliği ve kalabalık sınıf ortamları olarak da gösterilebilir. Benzer şekilde Karal, Reisoğlu ve Günaydın (2010) tarafından yapılan araştırmada bilişim teknolojileri sınıflarının kalabalık olması ve teknolojik yetersizlikleri sebebiyle öğretim programının uygulanışında sıkıntılarla karşılaşıldığını belirtmektedir. Bilişim teknolojileri sınıfı bulunmaması ya da FATiH projesinin uygulanması gerekçesiyle bilişim teknolojileri sınıfı donanımlarının güncellenmemesi okullarda öğretim programının hedeflerine ulaşılmasının önünde önemli bir engel olarak görünmemektedir. Öte yandan bilişim teknolojileri sınıfının olmaması sınıf yönetimi problemlerini de beraberinde getirmektedir. Bu sonuç bilişim teknolojileri öğretmenlerinin tükenmişlik düzeylerinin diğer branş öğretmenlerine göre daha yüksek olmasının nedenlerinden biri olarak gösterilebilir. Bu durum benzer şekilde Seferoğlu, Yıldız ve Yücel, (2014) tarafından yapılan çalışmanın bilişim teknolojileri öğretmenlerinin yaşadığı sıkıntılar ve bu sıkıntıların tükenmişlik düzeylerini artıırdığı yönündeki sonuçlarıyla örtüşmektedir.

Çeşitli araştırmalarda bilişim teknolojileri dersinin temel düzeyde bilgisayar kullanımı ve temel düzeyde gerekli programların öğretilmesini sağladığı ortaya konulmuştur (Dirisağlık, \& Kabakçı, 2009; Tanrı̈ğen, \& Özel, 2011). Bu nedenle bilişim teknolojileri dersinin gerekliliklerinin bir an önce yerine getirilmesi, laboratuvar olmayan okullarda bilişim teknolojileri sınıflarının oluşturulması ve varolan bilişim teknolojileri laboratuvarlarındaki eksikliklerin giderilmesi önemlidir.

Bilişim teknolojileri öğretmenlerinin derslerinde en sık kullandığı araç, gerecin dersle ilgili sunumlar ve projeksiyon olduğu ve ders kitabı olmamasının da önemli bir eksiklik olduğu sonucuna ulaşılmıştır. Ayrıca öğretmen görüşlerine göre çocuklara programlama öğretmek için gerekli donanımların eksik ya da güncelliğini kaybetmiş olması sebebiyle dersin işleniş̧inde önemli eksikliklerin ortaya çıktığı görülmüştür. Öte yandan öğretmenlerin güvenli bilişim 
teknolojileri kullanımı ile ilgili farkındalıklarının da yüksek düzeyde olmadığını göstermektedir (Sezer, Yilmaz, \& Karaoglan-Yilmaz, 2015) ve sadece donanımsal düzeyde eksiklerin değil, öğretmen ve öğrenci açısından farkındalık düzeyinde de eksiklerin olduğu söylenebilir.

Bilişim teknolojileri öğretmenlerinin derslerinde genel olarak klasik sınavlarla değerlendirme dışında başka yönteme başvurmadıklarını ve bu yöntem dışındaki yöntemlere başvurma ortam ve fırsatlarının olmadığı tespit edilmiştir. Buradan hareketle özellikle bilgisayar başına düşen öğretmen - öğrenci sayılarının fazlalığı ve farklı coğrafi bölgelere göre donanımsal açıdan bir sayısal uçurumun gözlenmesi (Yıldız, \& Seferoğlu, 2013) bu durumun nedenleri arasında gösterilebilir.

Bilişim teknolojileri öğretmenlerinin derslerinde en sık karşılaştığı sorunların başında ders ve çalışma kitaplarının olmaması, uygulamaya dayalı etkinliklerin gerçekleştirilememesi ve sınıflardaki BT dersiyle ilgili materyallerin yetersiz olmasıdır. Bilişim teknolojileri öğretmenleri mesleki hayatta karşılaştıkları zorluklar karşısında meslekleri ve dersleriyle ilgili kaygılarını dile getirirken hizmet öncesinde öğretmen adaylarının mesleğe karşı iyimser bakış açıları ve kendilerini teknolojiyle ilişkilendirmeleri dikkat çekicidir (Karataş, 2010).

Araştırmanın sonuçlarından hareketle elde edilen önerilere göre bilişim teknolojileri dersinin saatinin ve seçmeli/zorunlu olma durumuyla ilgili gerekli düzenlemelerin yapılırken öğrencilerin teknoloji kullanımlarına dair mevcut durumların kurumlarca göz önünde bulundurulması önemli ve gereklidir. Nitekim yapılan çalışmalarda ilkokuldan üniversite düzeyine kadar öğrencilerin bilişim teknolojilerini kullandığı ancak gelişen ve hızla değişen teknolojik koşulların oluşturduğu yeni durumlara ayak uyduracak yeterlilikte olmadığı, güvenli teknoloji kullanım davranışları sergilemedikleri görülmüştür (Çelen, Çelik, \& Seferoğlu, 2011; Karaoğlan-Yılmaz, Yılmaz, \& Sezer, 2014). Özellikle çocukların ve gençlerin bilişim teknolojileri araçları ile sürekli iç içe olmaları onların bilişim teknolojileri okuryazarlık düzeylerinin yüksek düzeyde olduğu anlamına gelmemektedir (Yıldız, Sarıtepeci, \& Seferoğlu, 2013). Öte yandan Bilişim Teknolojileri ve Yazılım dersi için önerilen yeni taslak müfredatta bu dersin kazanımlarının 1. sınıftan 4. sınıfa kadar tüm sınıflarda serbest zaman etkinliklerinde sınıf öğretmenlerince kazandırılması gerektiği ve bu dersin 21. yüzyıl yeterlilikleri kapsamında yer alan bilgi işlemsel düşünme gibi bazı becerilerin öğretilmesinde uygun olduğu görüşü göz çarpmaktadır (Talim ve Terbiye Kurulu Başkanlığı, 2016).

Ayrıca yeni bilişim teknolojileri ve yazılım dersi müfredatıyla birlikte dersin içeriği ve işlenişiyle ilgili ortaya çıkan/yaşanan sıkıntıları ayrıntılı olarak ortaya çıkarmak ve çözümler üretmek adına konuyla ilgili araştırmaların yapılması önerilebilir.

\section{KAYNAKLAR}

Akbıyık, C. ve Seferoğlu, S. S. (2012). İlköğretim Bilişim Teknolojileri dersinin işlenişi: Öğretmen görüş ve uygulamaları. Kuram ve Uygulamada Eğitim Bilimleri (KUYEB), 12(1), 405-424.

Akkoyunlu, B., \& Kurbanoğlu, S. (2003). Öğretmen adaylarının bilgi okuryazarlığı ve bilgisayar öz-yeterlik algıları üzerine bir çalışma. Hacettepe Üniversitesi Eğitim Fakültesi Dergisi, 24(24), 1-10. http://dergipark.ulakbim.gov.tr/hunefd/article/download/5000048750/5000046070 adresinden erişilmiştir.

Altun, E., \& Ateş, A. (2008). Bilgisayar ve öğretim teknolojileri öğretmen adaylarının sorunları ve geleceğe yönelik kaygıları. Illköğretim Online, 7(3), 680-692. 
Aykaç, N. (2011). Hayat bilgisi dersi öğretim programında kullanılan yöntem ve tekniklerin öğretmen görüşlerine göre değerlendirilmesi (Sinop ili örneği). Kastamonu Eğitim Fakültesi Dergisi, 19 (1), 113-126.

Bernstein, A. (1995). Author Envisions A World Without Work. New Yok News Day. Retriewed from http://www.foet.org/press/articles/EW/New\%20York\%20Newsday\%20September\%2024\%201995.pdf.

Crow, G. M. (2006). Complexity and the beginning principal in the United States: Perspectives on socialization. Journal of educational administration, 44(4), 310-325. Retriewed from http://www.emeraldinsight.com/doi/full/10.1108/09578230610674930.

Çelen, F. K., Çelik, A. ve Seferoğlu, S. S. (2011). Çocukların internet kullanımları ve onları bekleyen çevrim-içi riskler. XIII. Akademik Bilişim Konferansı (AB11). Inönü Üniversitesi, Malatya, 2-4.

Doyle, C. S. (1994). Information literacy in an information society: A concept for the information age. Diane Publishing.

Durdukoca, Ş. F., \& Arıbaş, S. (2011). Illköğretim Seçmeli Bilişim Teknolojileri Dersi 5. Basamak Öğretim Programinin Öğretmen Görüşleri Doğrultusunda Değerlendirilmesi, (Malatya Ili Örneği). Yüzüncü Yıl Üniversitesi Eğitim Fakültesi Dergisi, 8(1), 140-168 .

Dirisağlık, F. \& Kabakçı, I. (2009). Bilgisayar formatör öğretmenlerinin bilgi teknolojisi sınıflarının kullanımına ilişkin görüşleri: Eskişsehir ili örneği. Anadolu Üniversitesi Uluslararası Eğitim Teknolojisi Konferansı Kitabı. [Çevrim-içi: http://www.ietc2008.anadolu.edu.tr/content.php?pg=36], Erişim Tarihi: 12 Kasım 2015.

Dursun, Ö. Ö., \& Çuhadar, C. (2009, May). Bilgisayar öğretmeni adaylarının öğretmenlik mesleğine ilişkin düşünceleri. In Proceedings of 9 th International Educational Technology Conference.

Erdoğan, M., Kurşun, E., Tan Şişman, G., Saltan, F., Gök, A. ve Yıldız, i. (2010). Sınıf yönetimi ve sınıf içi disiplin problemleri, nedenleri ve çözüm önerileri üzerine nitel bir araştırma: Bilişim teknolojileri dersi örneği. Kuramdan Uygulamaya Eğitim Bilimleri, 10 (2), 853 891.

Gülcü, A., Aydın, S., \& Aydın, Ş. (2013). İlköğretim Okullarında Bilişim Teknolojileri Dersi Yeni Öğretim Programının Öğretmen Görüşlerine Göre Değerlendirilmesi. Karadeniz Sosyal Bilimler Dergisi, 8, 73-92.

International Society for Technology in Education (ISTE). (2016). ISTE Standarts for Students. Retriewed from https://www.iste.org/standards/standards/for-students-2016.

Karal, H., Reisoğlu, G. ve Günaydın, E. (2010). İlköğretim bilişim teknolojileri dersi öğretim programının değerlendirilmesi. Çukurova Üniversitesi Eğitim Fakültesi Dergisi, 38, 46-64.

Karaoğlan-Yılmaz, F., G., Yılmaz, R., \& Sezer, B. (2014). Üniversite öğrencilerinin güvenli bilgi ve iletişim teknolojisi kullanım davranışları ve bilgi güvenliği eğitimine genel bir bakış. Bartın Üniversitesi Eğitim Fakültesi Dergisi, 3(1), 176-199.

Karataş, S. (2010). Bilgisayar ve öğretim teknolojileri (BÖTE) öğretmen adaylarının mesleklerine ilişkin zihin haritalarının analizi (Gazi Üniversitesi Örneği). Ahi Evran Üniversitesi Eğitim Fakültesi Dergisi, 11(1), 159-173.

Morrison, K. (2012). School leadership and complexity theory. Routledge. 
Nam, C. S., \& Smith-Jackson, T. L. (2007). Web-based learning environment: A theory-based design process for development and evaluation. Journal of Information Technology Education, 6, $23 . \quad$ Retriewed from https://www.learntechlib.org/p/111406/article_111406.pdf.

Phelps, R., Hase, S., \& Ellis, A. (2005). Competency, Capability, complexity and computers: Exploring a new model for conceptualising end-user computer education. British Journal of Educational Technology, 36, 67-84.

Seferoğlu, S. S. (2008). ilköğretim okullarında teknoloji kullanımı: Yaşanan sorunlar, gözlemler ve çözüm önerileri. Eğitimde Küreselleşme ve Bilişim Teknolojileri I. Uluslararası Konferansı Bildiriler Kitabı (Tahsilde Qloballaşma ve IKT Mövzusunda Beynelxalq Konfransın Materialları), 45-53. Azerbaycan Devlet Pedagoji Üniversitesi ve Hacettepe Üniversitesi. Bakü, Azerbaycan.

Seferoğlu, S. S., Yıldız, H., \& Yücel, Ü. A. (2014). Öğretmenlerde tükenmişlik: Tükenmişliğin göstergeleri ve bu göstergelerin çeşitli değişkenler açısından incelenmesi. Eğitim ve Bilim, 39(174), 348-364.

Sert, G. (2010). Öğretim teknolojileri alanında yayımlamış Türkiye adresli makalelerin içerik analizi. Yayımlanmamış Yüksek Lisans Tezi, Hacettepe Üniversitesi, Fen Bilimleri Enstitüsü, Ankara.

Sezer, B., Yilmaz, R., \& Karaoglan-Yilmaz, F. G. (2015). Cyber bullying and teachers' awareness. Internet Research, 25(4), 674-687.

Tanrıöğen, A. ve Özel, A. (2011). Bilişim teknolojileri okul formatörü öğretmenlerinin bilişim teknolojisi sınıflarına ilişkin görüşleri (Denizli ili örneği). e-Journal of New World Sciences Academy, 6 (1), 219-230.

Talim ve Terbiye Kurulu Başkanlığı (2006). Illköğretim bilgisayar dersi (1-8. sınıflar) öğretim programı. [Çevrim-içi: http://ttkb.meb.gov.tr/ogretmen ], Erişim Tarihi: 12 Kasım 2015.

Talim ve Terbiye Kurulu Başkanlığı (2007). Yeni Uygulamaya konulan ilköğretim kurumları derslerine ait öğretim programları ve haftalık ders saatleri çizelgesine ilişkin hususlar. [Çevrim-içi:

http://canakkale.meb.gov.tr/duyurular/E_Okul_Projesi/2007_ogrt_yili_ilkogretim_kurumlari_dersleri ne_iliskin_hususlar.pdf ], Erişim Tarihi: 12 Kasım 2015.

Talim ve Terbiye Kurulu Başkanlığı (2010). ilköğretim okulları haftalık ders çizelgesi. [Çevrim-içi: http://ttkb.meb.gov.tr/ogretmen/modules.php?name=Downloads\&d_op=getit\&lid=802 .], Erişim Tarihi: 12 Kasım 2015.

Talim ve Terbiye Kurulu Başkanlığı (2013). Ortaokul yeni ders programı. [Çevrim-içi: http://mebk12.meb.gov.tr/meb_iys_dosyalar/63/08/745166/dosyalar/2013_05/280508 43_ortaokul_yeni_ders_programi.pdf], Erişim Tarihi: 12 Kasım 2015.

Talim ve Terbiye Kurulu Başkanlığı, (2016). Bilişim teknolojileri ve yazılım dersi öğretim programı-2017. [Çevrim-içi: http://mufredat.meb.gov.tr/Dosyalar/2017113165849845Bili\%C5\%9Fim\%20Teknolojileri\%20ve\%20Yaz\%C4\%B1|\%C4\%B1m\%20Dersi\%20\%C3\%96\% C4\%9Fretim\%20Program\%C4\%B1.pdf], Erişim Tarihi: 7 Şubat 2017.

Yıldııım, A. \& Şimşek, H. (2005). Sosyal bilimlerde nitel araştırma Yöntemleri.Ankara: Seçkin.

Yıldız, H., Sarıtepeci, M., \& Seferoğlu, S. S. (2013). FATiH Projesi Kapsamında Düzenlenen Hizmet-lçi Eğitim Etkinliklerinin Öğretmenlerin Mesleki Gelişimine Katkılarının ISTE 
Ortaokullarda Bilişim Teknolojileri ve Yazılım Dersinin İşlenişi, Yaşanan Problemler ve Çözüm Önerileri: Öğretmen Görüşleri

Öğretmen Standartları Açısından İncelenmesi. Hacettepe Üniversitesi Eğitim Fakültesi Dergisi, Özel Sayı (1), 375-392.

Yıldız, H., \& Seferoğlu, S. S. (2013). Sayısal uçurumun önlenmesinde eğitimin işlevi ve bilişim teknolojileri öğretmenlerinin bu süreçteki rolü. Middle Eastern and African Journal of Educational Research (MAJER), 3, 69-79. 


\section{SUMMARY}

Information technology, which has become an indispensable part of our life, brings with it many changes. With these changes, there are also transformations in the expectations from the learners in today expressed as information society. Depending on the requirements of this motion technology projects conducted by the Ministry of Education to the establishment of various hardware infrastructure in public schools. On the other hand, students of secondary schools with ICT applications to ensure that meet at an earlier age and to acquire the necessary qualifications 5th and 6th grade in Information Technology course is made mandatory. However, in some schools during the transition of schools in the $4+4+4$ system and during FATIH project implementations, the Information Technology classes have been removed or not hardware-updated. Many compulsory ICT in schools is a result of this course of treatment it lacks opportunities. In this case, information technology remains a serious problem in front of their teachers. However, type in the information technology how it is processed in the absence of information technology class of course, this is a major shortcoming of how compensation had that in the course of these teachers did not reveal any studies that they confront what other problems. As a result, many schools in the compulsory courses are taught in Information Technology and Software deprived of opportunities. At this point, the aim of this study ICT secondary school information technology course to examine how committed and to identify problems encountered in the course.

Mixed methods were used including both quantitative and qualitative dimensions of this study. While more participants are attained through the quantitative approach in the mixed approach, it allows for deeper processing of the topic covered by qualitative methods. In this study, explanatory design of mixed method was used. For this purpose, the data was collected from 50 information technology teachers in secondary schools in 31 different provinces of Turkey during the fall semester of 2015-2016. The data were collected by "Demographic questionnaire", "processing of information technologies in the course of the survey" and "semi-structured form of the obstacles and suggestions in the handling of the information technology course" developed by the researchers.

Acording to the findings of the research, it is understood that teaching and demonstration methods are the most frequently used methods of information technology teachers. On the other hand, six hats and working methods of the project has been used less frequently than other methods. This can be said to be maintained with a teacher-centered approach in teaching computing technologies. According to participant's opinion, it is understood that the most common tools used by the teachers of ICT in their lessons are presentations about the lesson. Along with that, acording to teachers' opnions seem to feel the lack of an important tool like a textbook. It was found that the teachers of ICT used the classical examination methods most frequently in their lessons. It is seen that the evaluation method that teachers use the least in their lessons is the peer evaluation.

Information technology by teachers in the absence of the most common early problems faced lessons and workbooks, practice based on the effectiveness of the failure and insufficient to be of material related to the IT courses in range / no is the problem. The problems faced by the teachers and students at least seem to have a negative attitude towards the course.

Within the scope of the research, the most frequently used methods of information technology teachers were to explain and demonstrate, and the least used methods were 6 hat and project study methods. Similarly, Akbıyık and Seferoğlu (2012) were stated that most of the participants used projection, narration, demonstration methods in the learning-teaching activities. Some of the reasons for this situation may also be indicated in the laboratory as a lack of equipment / inadequacy and crowded classroom environments. Regarding this situation, Karal, Reisoğlu and Günaydın (2010) stated that there is a problem in the implementation of the curriculum because of the crowded classes and technological inadequacies in the course of ICT.

Information technology tools that are most often used by teachers, lesson materials about the course of the presentation and projection of the book reached the conclusion that in the absence of a significant deficiency. In addition, the lack of the necessary software to teach programming to children according to their teachers' opinions were seen as a major deficiency in the course of processing. Information technology teachers they resort to other methods outside the formal examination and evaluation concluded that the lessons of this resort to methods other than setting method and 
Ortaokullarda Bilişim Teknolojileri ve Yazılım Dersinin İşlenişi, Yaşanan Problemler ve Çözüm Önerileri: Öğretmen Görüşleri

opportunity were obtained. Information technology by teachers in the absence of the most common problems faced by the beginning of the course and workbooks, practice-based activities can not be carried out and that the materials related to insufficient IT lessons in class / is not. ICT research based on the results of the action on the recommendations obtained by the time of elective courses and / changes related to the case to be necessary to take into account the related institutions while the current situation is important and necessary. 